\title{
Torsion Fracture Behavior of Drawn Pearlitic Steel Wires with Different Heat Treatments
}

\author{
Wang Zhijia ${ }^{a}$, Wu Xiaolei ${ }^{b}$ and Hong Youshic \\ LNM, Institute of Mechanics, Chinese Academy of Sciences, Beijing 100080, China \\ awangzhj@Inm.imech.ac.cn, ${ }^{b} x l w u @ i m e c h . a c . c n,{ }^{c h}$ hongys@imech.ac.cn (corresponding author)
}

Keywords: Pearlite, steel wire, heat treatment, torsion tests, DSC, strain aging, recovery

\begin{abstract}
In this paper, torsion fracture behavior of drawn pearlitic steel wires with different heat treatments was investigated. Samples with different heat treatment conditions were subjected to torsion and tensile tests. The shear strain along the torsion sample after fracture was measured. Fracture surface of wires was examined by Scanning Electron Microscopy. In addition, the method of Differential Scanning Calorimetry was used to characterize the thermodynamic process in the heat treatment. A numerical simulation via finite element method on temperature field evolution for the wire during heat treatment process was performed. The results show that both strain aging and recovery process occur in the material within the temperature range between room temperature and $435^{\circ} \mathrm{C}$. It was shown that the ductility measured by the number of twists drops at short heating times and recovers after further heating in the lead bath of $435^{\circ} \mathrm{C}$. On the other hand, the strength of the wire increases at short heating times and decreases after further heating. The microstructure inhomogeneity due to short period of heat treatment, coupled with the gradient characteristics of shear deformation during torsion, results in localized shear deformation of the wire. In this situation, shear cracks nucleate between lamella and the wire breaks with low number of twists.
\end{abstract}

\section{Introduction}

Cold drawn pearlitic wires are mainly employed by the cable industry for applications such as tire reinforcement, suspension cables, springs, etc. Cold drawing is applied to increase the mechanical strength of the wires [1]. Some high-strength cold drawn wires are twisted into cables and bunches. As a result, not only must the wire have high tensile strength, it also must have good torsional ductility. Torsional ductility is evaluated by the number of twists to failure for a standardized gauge length [2]. In some applications, the wire has to be galvanized to protect it from the corrosion in the environment [3]. The hot dip galvanizing process is commonly conducted within the bath of about $430-460{ }^{\circ} \mathrm{C}$. It has been known that the temperature arise involved in treatment process plays a prominent role in torsional ductility [4]. Thus, this study attempts to investigate the effect of heat treatment on the microstructure and torsion behavior of drawn pearlitic wires. Samples were heat treated for $12,60,120$ and 240 seconds in a lead bath of $435^{\circ} \mathrm{C}$ and then subjected to torsion and tensile tests. The torsional ductility measured by the number of twists to fracture drops at heating of 12 seconds and recovers after further heating. On the other hand, the ultimate tensile strength (UTS) shows a peak at 12 seconds. These changes in mechanical properties are discussed based on Scanning Electron Microscopy (SEM) observations, Differential Scanning Calorimetry (DSC) measurements and temperature field evolution simulations.

\section{Experimental Procedure}

The original material used in this study was $13 \mathrm{~mm}$ diameter steel rod. The basic chemical composition is (in wt\%): C, 0.85 0.90; Si, 0.12 0.32; Mn, 0.60 0.90. The rods were with fully pearlitic microstructure and then drawn through eight dies to wires of $7 \mathrm{~mm}$ in diameter. Microstructure examinations were performed on wires without heat treatment. Standard mounting and polishing procedures were used for preparation of samples for microstructure observations on 
longitudinal section and cross section of the wire. Samples were nital etched and microstructures were examined by SEM.

Samples of drawn wires were heat treated for $12,60,120$ and 240 seconds in a lead bath of $435^{\circ} \mathrm{C}$ and then subjected to torsion and tensile tests. Tensile testing was carried out to get wire UTS. Number of twists to failure was obtained in torsion testing on a $700 \mathrm{~mm}(\Phi 7 \mathrm{~mm} \times 100)$ gauge length.

For DSC experiment, the sample was made from as drawn wires. It was heated from room temperature (RT) to $700{ }^{\circ} \mathrm{C}$ by an ETZSCH DSC 404C instrument. Heat flow into sample was measured as a function of temperature.

After a number of twists, the generatrix of the wire took helix morphology, leaving traces on the wire surface (Fig. 1). The angle between the trace and wire axis $(\alpha)$ was measured for all fractured specimens. Then, the shear strain $\gamma$ along the torsion sample after fracture is derived from angle $\alpha$, i.e. $\gamma=\tan \alpha$. For specimen with the number of twists $N$, the applied shear strain $\gamma_{a}$ was derived from $\pi d N / l$, where $d$ and $l$ are the specimen diameter and gauge length, respectively.
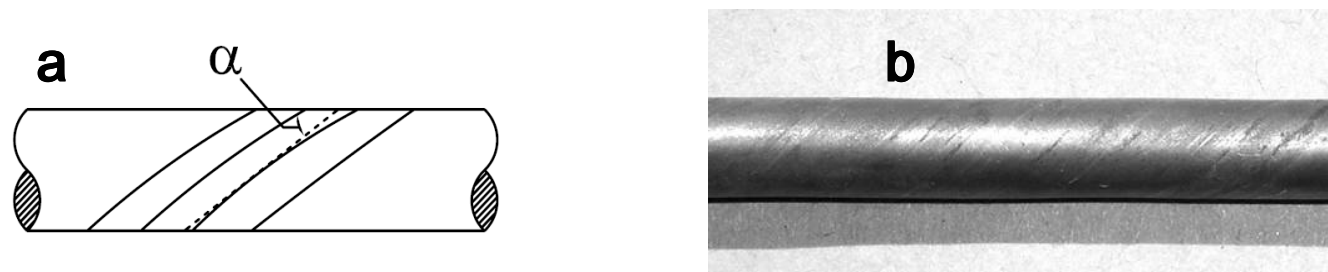

Fig. 1 Deformation traces on wire surface: (a) illustration, and (b) an example.

As for torsion fracture surface investigation, samples were cleaned in alcohol using an ultrasonic washing unit. Representative SEM micrographs were taken of samples with different heat treatment conditions.

\section{Numerical Model of Temperature Field Simulation}

Under heating environments, transitions occur within the specimens. The energy corresponding to these transitions, which is known as latent heat, affects temperature distribution in the wire. For this case, the latent heat and the corresponding temperature ranges were measured by DSC. The wire has a cylindrical shape and the controlling equation with latent heat under axisymmetric coordinate system is introduced:

$$
\rho L_{i} \frac{\partial \sum f_{i}}{\partial t}+\frac{1}{r} \frac{\partial}{\partial r}\left(r k \frac{\partial T}{\partial r}\right)=\rho C \frac{\partial T}{\partial t}
$$

where $T$ and ${ }^{t}$ are temperature and time variables, $\rho$ is mass density, $k$ is thermal conductivity, $C$ is specific heat and $r$ is the coordinate referring to the distance measured from wire axis. The first term on the left side of Eq. 1 corresponds to latent heat. ${ }^{L_{i}}$ is the latent heat dismissed by unit volume of material in the ${ }^{i}$ th reaction, and $f_{i}$ is the portion of material that has finished the $i$ th reaction. We make the following assumptions in the numerical modeling: (1) the wire and heating media is in full contact so that the boundary temperature is chosen at the temperature of the heating media: $T\left(r_{0}, t\right)=T_{m}$ with $r_{0}$ being wire radius and $T_{m}$ being media temperature and (2) $f$ takes the form of linear relation with temperature: 


$$
f_{i}=\left\{\begin{array}{ll}
\frac{T_{L i}-T}{T_{L i}-T_{S i}} & T_{S i} \leq T \leq T_{L i} . \\
0 & \text { others }
\end{array} .\right.
$$

Here $T_{S i}$ and $T_{L i}$ are the starting and ending temperature of the $i$ th reaction, respectively.

For solution through standard finite element method (FEM), Eq. 1 can be expressed as:

$$
\frac{1}{r} \frac{\partial}{\partial r}\left(r k \frac{\partial T}{\partial r}\right)=\rho\left(C-L_{i} \frac{\partial \sum f_{i}}{\partial t}\right) \frac{\partial T}{\partial t} .
$$

Then Eq. 3 is solved using standard finite element codes ANSYS with specific heat submitted by $C-L_{i} \partial \sum f_{i} / \partial t$ calculated through Eq. 2 .

\section{Results and Discussion}

Fig. 2 shows the microstructure morphology of as drawn wires. It appears clearly that pearlite colonies are elongated in the dawning direction and curled about wire axis in the cross section. This effect results from the inadequacy of the axisymmetric deformation imposed by the drawing process and of the cubic symmetry of the ferrite phase [5].
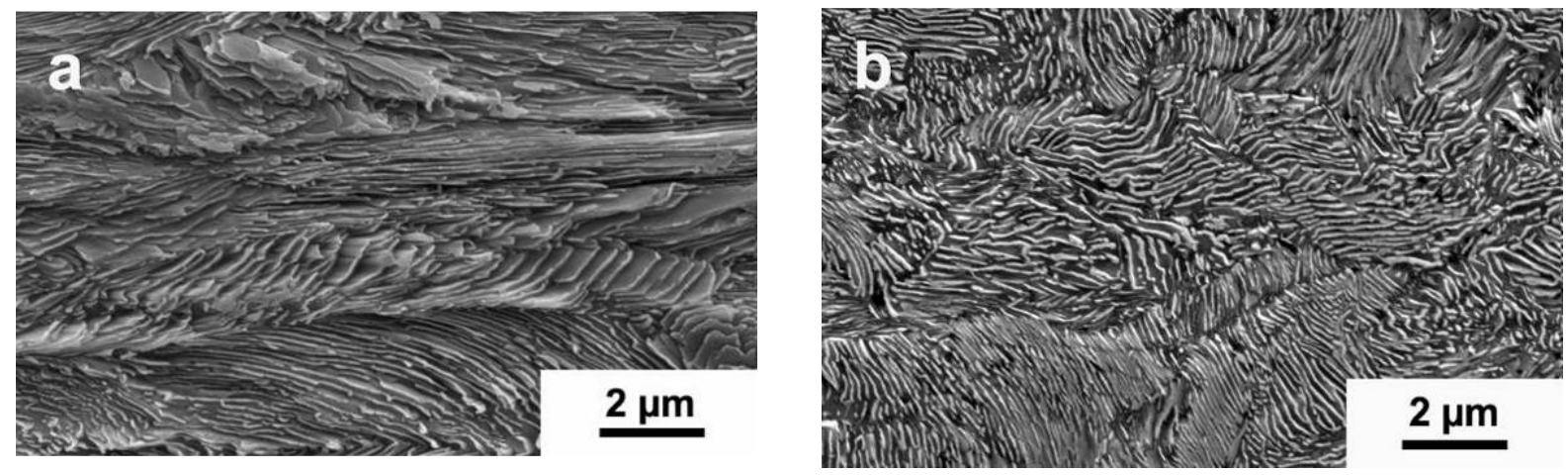

Fig. 2 Microstructure of deformed pearlitic colonies: (a) longitudinal section, and (b) cross section.

The results of torsion and tensile tests are shown in Fig. 3. For each heat treatment condition, five specimens were used in torsional and tensile tests, respectively. Namely, each datum point in Fig. 3 is an average from five specimens. It is seen that the ultimate tensile strength peaks at short heat treatment times and then falls as heating continues. There is a corresponding trough in the torsional ductility at short heat treatment times, which then recovers.

The DSC results show that transitions occur within the material in three temperature ranges (Fig. 4). These transitions are centered at approximate 115,400 and $620^{\circ} \mathrm{C}$. The first two transitions are within the temperature range of the present heat treatment. The first change is thought to be related to strain aging. During drawing process, ferrite phase experiences plastic deformation while cementite acts as barriers to slip in ferrite. The interlamellar spacing of pearlite approximately equals the maximum slip distance. Hence, a large number of dislocations have accumulated at the ferrite-cementite interface in the as drawn wires. At low temperatures, carbon atoms in ferrite and cementite transfer to dislocations to lower the free energy of the system. The carbon atmosphere around dislocations impedes dislocation movement during the following mechanical testing, leading to an increase in strength and decrease in ductility. The second change is thought to be thermal responses of further recovery and recrystallization process. Recrystallization temperature of carbon steels decreases as the increase of carbon content and the extent of plastic deformation. For the 
present material, it has a carbon content of $0.85 \sim 0.90 \mathrm{wt} \% \mathrm{C}$ and drawing strain of about 1.5 . It is reasonable to estimate that the cold worked pearlitic structure will recrystallize in the temperature range of $350 \sim 400{ }^{\circ} \mathrm{C}$.
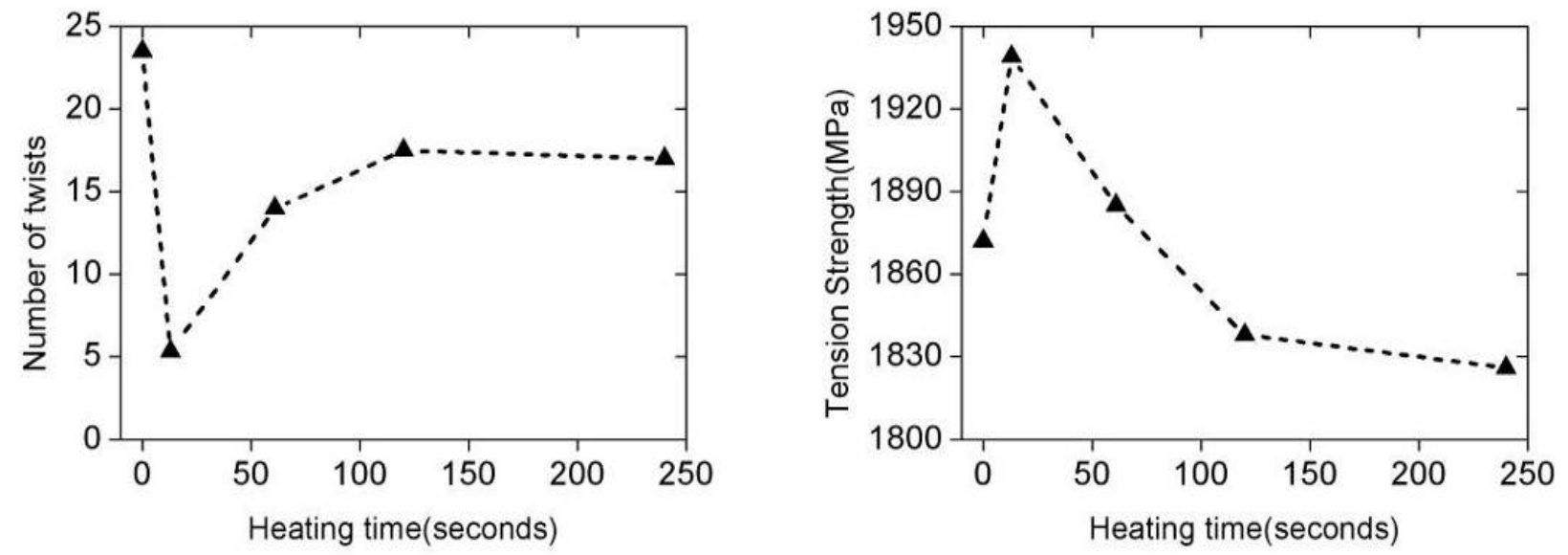

Fig. 3 Variation of wire UTS and number of twists to failure with heating times.

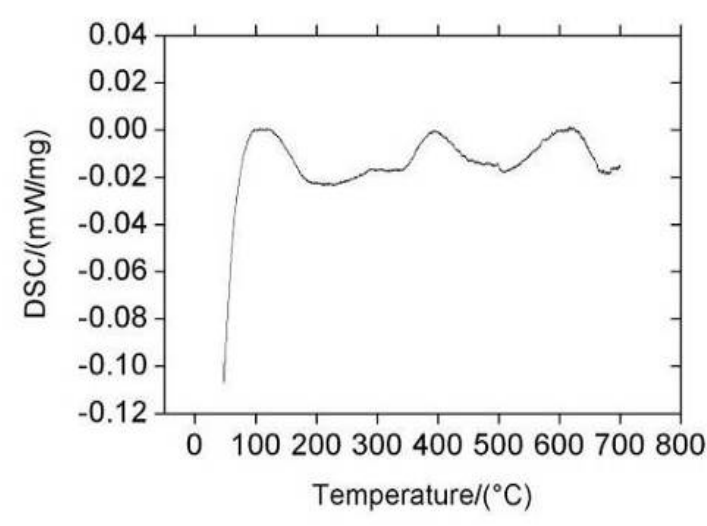

Fig. 4 DSC curve for wire heated at $20 \mathrm{~K} / \mathrm{min}$.

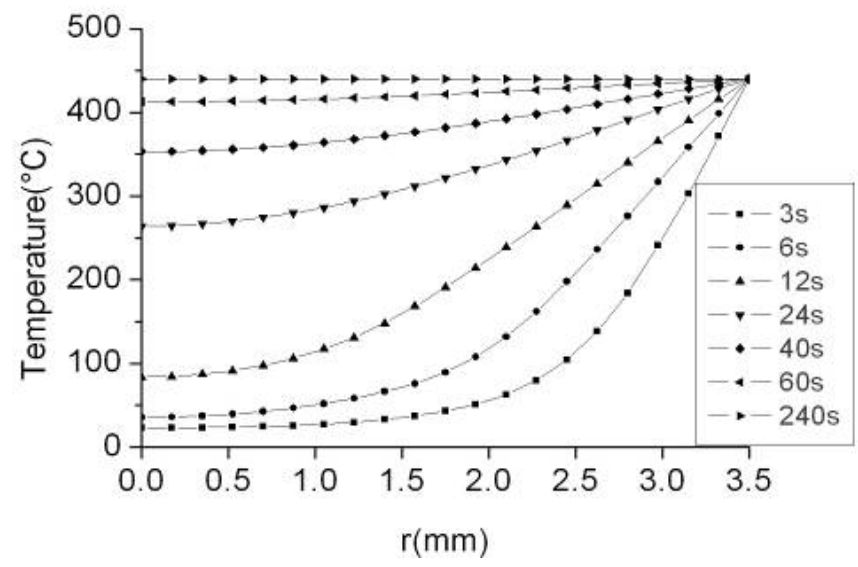

Fig. 5 Simulation results of temperatureevolution during heat treatment

The results of torsional and tensile tests provide evidences for strain aging and recrystallization process. At heating time of 12 seconds, carbon atoms diffuse to and pin dislocations. During the stage, tensile strength increase from 1870 to about $1940 \mathrm{MPa}$. As heat treatment progresses to longer times, the strength drops significantly and the ductility recovers. This can be understood by a further recovery and recrystallization process in the material.

For temperature field simulation, the thermal effect of strain aging (referred to as reaction 1) and recrystallization process (referred to as reaction 2) at about $400{ }^{\circ} \mathrm{C}$ is incorporated. The thermal-physical properties used for calculation are listed in Table 1.

Fig. 5 shows the simulation results of temperature field evolution during heat treatment. For the case with heat treatment of 12 seconds, it is seen that the material in the $r$ range of $1.5 \sim 2.5 \mathrm{~mm}$ is in the temperature range of $100 \sim 350^{\circ} \mathrm{C}$. This part of specimen is in strain aging status. In the meantime, the temperature in outer part of the specimen is higher and close to $435^{\circ} \mathrm{C}$ near the surface which will lead to the further recovery and recrystallization process in the material. 
Table 1 Thermal-physical properties used for temperature field calculation

\begin{tabular}{cccccc}
\hline \multicolumn{5}{c}{$k=54\left[\mathrm{~W} \cdot \mathrm{m}^{-1} \cdot \mathrm{K}^{-1}\right] ;$} & $\rho=7833\left[\mathrm{~kg} \cdot \mathrm{m}^{-3}\right] ; C=445\left[\mathrm{~J} \cdot \mathrm{kg}^{-1} \cdot \mathrm{K}^{-1}\right]$ \\
\hline$T_{L 1}$ & $T_{S 1}$ & $T_{L 2}$ & $T_{S 2}$ & $L_{1}$ & $L_{2}$ \\
\hline $70\left[{ }^{\circ} \mathrm{C}\right]$ & $170\left[{ }^{\circ} \mathrm{C}\right]$ & $350\left[{ }^{\circ} \mathrm{C}\right]$ & $450\left[{ }^{\circ} \mathrm{C}\right]$ & $4 \times 10^{3}\left[\mathrm{~J} \cdot \mathrm{kg}^{-1}\right]$ & $2 \times 10^{3}\left[\mathrm{~J} \cdot \mathrm{kg}^{-1}\right]$ \\
\hline
\end{tabular}

The torsion fracture behavior could be divided into two groups in accordance to their fracture morphologies. For wires with a significant number of applied torsional twists, smooth and flat fracture surfaces develop on transverse wire surfaces (Fig. 6a). For those with degraded torsion behavior, the wire split into layers in longitudinal direction during torsion. With increased twisting, the longitudinal cracks assume a helical or spiral orientation, as shown in Fig. 6b. The longitudinal splitting is named delamination in literature which is a typical indications of a decrease in ductility.
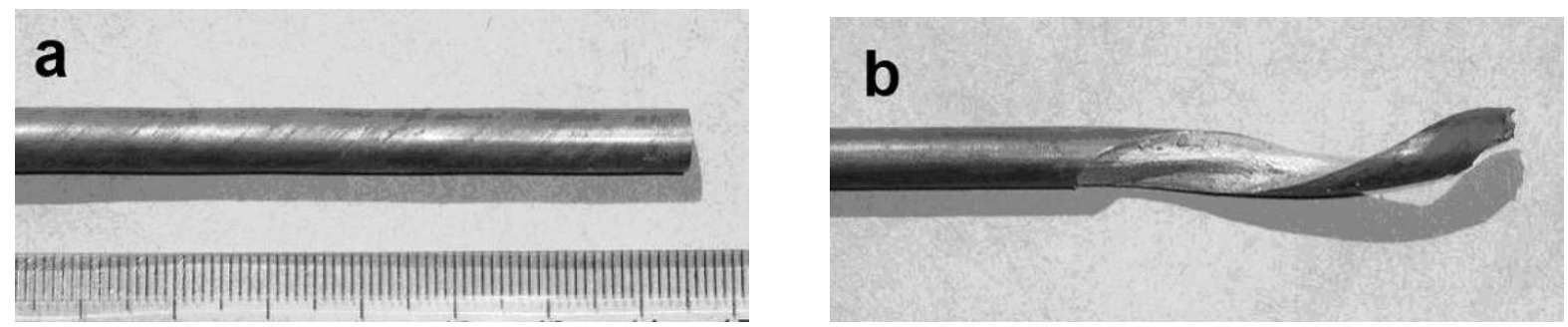

Fig. 6 Fracture surfaces of wires with (a) high and (b) low number of twists to fracture.
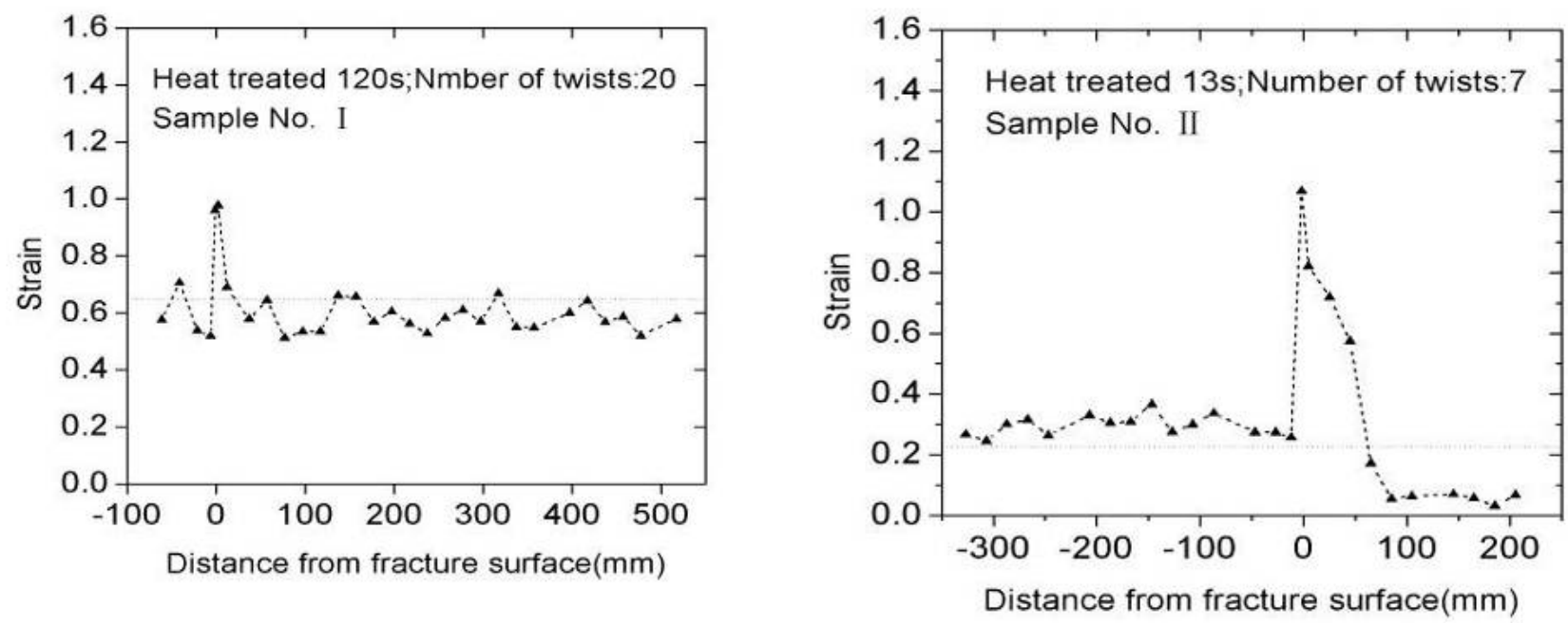

Fig. 7 Two examples of shear strain distribution along wire axis.

The shear strain distribution along axis also differs between the two groups. Fig.7 shows two examples of measured shear strain of wires with number of twists 20 and 7, respectively. For the sample with 20 twists, shear strain is approximately uniform along axis except for the region near the fracture surface. On the other hand, for the sample with 7 twists, shear strain away from the fracture region is very low while the value is much larger near the fracture surface. The ratio of the maximum strain at fracture to applied strain is calculated for all tested specimens. For wires with the number of twists above and below 11 (which is the required value of the qualified product), the value is 1.6 and 5.2 , respectively. The large difference of the two values indicates that localized deformation occurred on wires with degraded torsion performance.

Fig. 8 shows the SEM photographs of different fracture surfaces. It is seen that the flat fracture surface is composed of elliptical dimples and gliding trace. This is typical of ductile fracture related to shear stress [6]. The delamination surface is characterized by quasi-cleavage indicating increased brittleness of wires. 

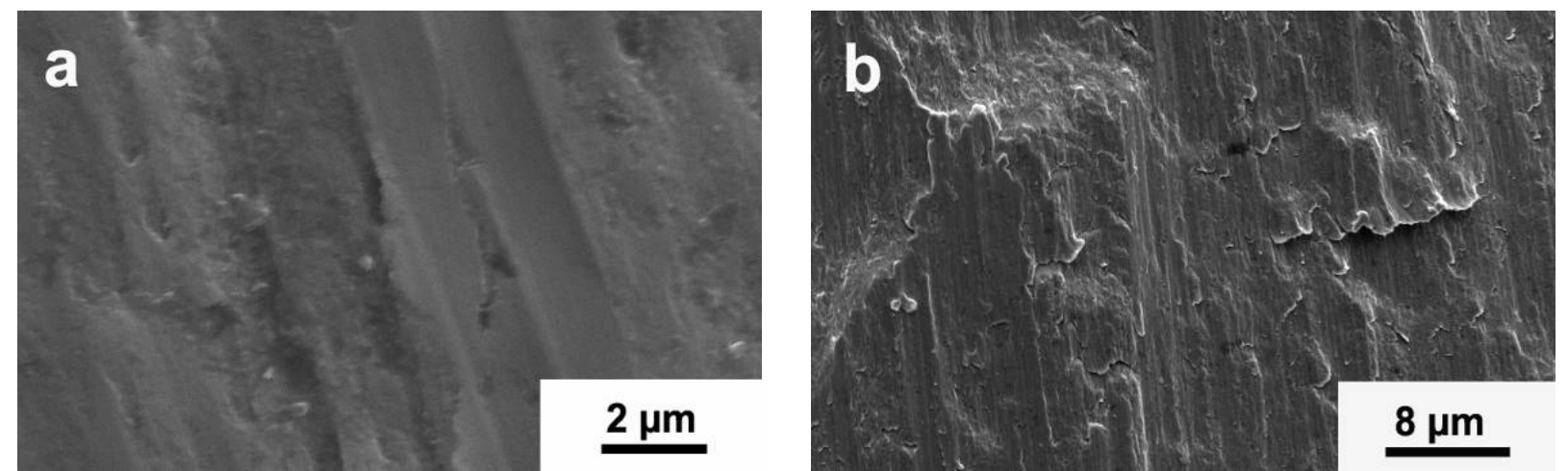

Fig. 8 SEM photographs of torsion fracture surface (a) flat shear fracture, and (b) delamination.

As demonstrated through simulation, temperature field is not uniform along the radius at heat treatment of 12 seconds. This indicates that microstructure evolution controlled by temperature will differ. Interior part of specimen is in strain aging status while recrystallization occurs near the surface of wire. When subjected to torsional loading, the specimen tends to shear deformation localization which induces shear crack. As twist continues, the crack develops, deformation localizes and the specimen fractures. For specimens with heat treatments of 60 seconds or longer, the upgraded torsion behavior with large number of twists is attributed to the recrystallization structure along wire radius.

\section{Conclusions}

Based on the above investigation, it can be concluded that:

1. Short time heat treatment at $435^{\circ} \mathrm{C}$ for cold drawn pearlitic wires leads to a peak in ultimate tensile strength and a corresponding drop in torsional ductility.

2. The material experiences both strain aging and recrystallization in the temperature range of the present heat treatment. Strain aging happens in temperature range around $150^{\circ} \mathrm{C}$. Further recovery and recrystallization process activate at higher temperatures.

3. Torsional ductility degradation is attributed to strain aging effect and nonuniform evolution of microstructures along wire radius with respect to the temperature field during heat treatment.

\section{Acknowledgement}

The authors would acknowledge Bao Shan Iron \& Steel Co., Ltd. and National Scientific Foundation of China $(10472117,50471086)$ for supporting this research. The authors would also acknowledge Dr. Ge Fei, Dr. Xie Jijia and Mr. Xie Ziling for their assistance in this investigation.

\section{References}

[1] J. D. Embury, R. M. Fisher: Acta Mater. Vol. 14, (1966), p.147.

[2] U. D. Haene, I. Lefever and W. V. Raemdonck, Wire J. Int. June, (1994), p.68.

[3] H. F. Zhong, B. J. Liu and Q. F. Zhang: J. Iron Steel Res. Vol. 14 (2002), p.65 (In Chinese).

[4] R. Ogawa, Y. Kanetsuki and Y. Hirai: Kobe Res. Dev. (1985), p.1127.

[5] M. Zelin: Acta Mater. Vol. 50 (2002), p.4431.

[6] A. Phillips: Electron Fractography Handbook (Metals and Ceramics Information Center 1976). 
Advances in Fracture and Materials Behavior

10.4028/www.scientific.net/AMR.33-37

Torsion Fracture Behavior of Drawn Pearlitic Steel Wires with Different Heat Treatments 10.4028/www.scientific.net/AMR.33-37.41

\section{DOI References}

[1] J. D. Embury, R. M. Fisher: Acta Mater. Vol. 14, (1966), p.147.

doi:10.1016/0013-4686(66)80063-4

[3] H. F. Zhong, B. J. Liu and Q. F. Zhang: J. Iron Steel Res. Vol. 14 (2002), p.65 (In Chinese). doi:10.1002/cjoc.20020201151

[5] M. Zelin: Acta Mater. Vol. 50 (2002), p.4431.

doi:10.1023/A:1015180912228 